\title{
Análise da dinâmica da paisagem no município de Rio Verde, Goiás, Brasil: uma ferramenta para a escolha de áreas prioritárias para a conservação
}

\author{
Analysis of the landscape dynamics in the municipality of Rio \\ Verde, Goiás, Brazil: a tool to choose priority areas for conservation
}

\author{
Mariana Nascimento Siqueira ${ }^{1}$ \\ Karla Maria Silva de Faria ${ }^{2}$
}

\begin{abstract}
Resumo
Em uma paisagem, é importante considerar a sua dinâmica para entender as causas da perda de habitat e a relação dela com outros elementos para propor áreas prioritárias para a conservação da biodiversidade. Neste estudo, a paisagem nos anos de 1987 e 2016 do município de Rio Verde, Goiás, Brasil, foi analisada. Esse município tem uma economia essencialmente agrícola e, desse modo, os seus habitats naturais foram convertidos em paisagem antrópica. A análise inicial foi realizada por meio da interpretação das imagens do satélite Landsat para os anos de 1987 e 2016, nas quais foram identificadas: 1) aumento nas áreas agrícolas; 2) redução nas áreas de pastagem; 3) redução nas áreas de formação de savanas; 4) aumento nas áreas de formação florestal; e 5) aumento nas áreas de formação campestre. Como resultado, as áreas de pastagens abandonadas ou áreas de formação de savanas que foram alteradas ao longo dos anos foram ocupadas por áreas de formação campestre. Com base em métricas de paisagem obtidas do software Fragstats, observou-se que o isolamento não foi alterado entre a classe analisada, com exceção das áreas urbanas e da água. Em 2016, o município de Rio Verde possuía 198 fragmentos de vegetação nativa maiores do que 100 hectares, portanto, tais fragmentos são os mais prioritários para conservar a biodiversidade local.
\end{abstract}

Palavras-chave: Fragmentação; Perda de Habitat; Fragstats; Isolamento; Cerrado.

\begin{abstract}
In a landscape, it is important to consider its dynamic to understand the causes of habitat loss and the relationship of this landscape with other elements to propose priority areas for biodiversity conservation. In the present study, we considered the municipality of Rio Verde (GO) and
\end{abstract}

\footnotetext{
1 Universidade de Rio Verde, Rio Verde, Goiás, Brasil. mns.mariana@gmail.com

${ }^{2}$ Universidade Federal de Goiás, Goiânia, Goiás, Brasil. karla_faria@ufg.com

Artigo recebido em: 18/06/2017. Aceito para publicação em: 13/06/2019.
} 
analyzed its landscape in the years of 1987 and 2016. This municipality has an essentially agricultural economy and, therefore, its natural habitats had been converted in the anthropic landscape. We conducted the initial analysis interpreting the images of Landsat satellite for the years of 1987 and 2016, where we characterized: 1) increase in the agriculture areas; 2) reduction in the pasture areas; 3) reduction in the areas of savanna formation; 4) increase in the areas of forest formation; and 5) increase in the areas of Grassland formation. We observed that those areas of abandoned pasture or areas of savanna formation that were altered over the years were occupied by areas of Grassland formation. Based on landscape metrics obtained from Fragstats software, we observed that isolation was not altered among the analysed class, with the exception of urban areas and water. In 2016, the municipality of Rio Verde had only 198 fragments of native vegetation with more than 100 hectares, therefore, we suggest such fragments are the most priority to conserve the local biodiversity.

Keywords: Fragmentation; Habitat loss; Fragstats; Insulation; Cerrado.

\section{Introdução}

O atual período histórico já pode ser visto como a sexta extinção em massa de espécies, devido, principalmente, às mudanças no processo de uso e ocupação do solo sem critérios conservacionistas (CEBALLOS et al., 2015). Segundo Santos e Câmara (2002), os impactos sobre os ecossistemas ocorrem em função do processo de ocupação do território, realizado, historicamente, mediante o uso de práticas econômicas e sociais arcaicas que se desenvolveram fundadas na ideia da inesgotabilidade dos recursos naturais, processo que aumentou consideravelmente nas últimas três décadas.

Neste contexto de degradação, também se insere o Cerrado, o qual foi considerado por Mittermeier et al. (2004) como um dos 34 hotspots de biodiversidade, por apresentar um alto índice de espécies endêmicas submetidas a um elevado nível de degradação ambiental. Devido a essa degradação elevada, esse bioma pode estar perdendo espécies ainda desconhecidas pela ciência (DINIZ-FILHO et al., 2005). Além do mais, diante da sexta extinção em massa, pode ser que a oportunidade para evitar a deterioração da biodiversidade esteja passando rapidamente, o que irá 
resultar na perda de serviços ecossistêmicos em diferentes escalas (CEBALLOS et al., 2015).

Beuche et al. (2015) concluíram que em 2010, a cobertura natural de remanescentes de Cerrado já havia reduzido para $47 \%$ no território brasileiro. Este cenário pode ser ainda pior, pois, segundo Soares Filho et al. (2014), as atuais políticas ambientais brasileiras ainda permitirão desmatamentos adicionais no Cerrado. Ceballos et al. (2015) chamam a atenção para a urgência em intensificar esforços de conservação diante do cenário atual. Nesse sentido, uma das ações a ser realizada é o mapeamento de áreas frágeis, do ponto de vista ambiental, que possam estar perdendo cobertura vegetal em taxas superiores as necessárias para manutenção de determinados serviços ecossistêmicos.

É nesse sentido que as pesquisas em ecologia da paisagem contribuem com os esforços voltados para conservação da biodiversidade e de serviços ecossistêmicos, pois apresentam duas principais abordagens. Uma delas é a geográfica, que privilegia o estudo da influência do homem sobre a paisagem e a gestão do território; a outra é a ecológica, que enfatiza a importância do contexto espacial sobre os processos ecológicos e a importância das relações estabelecidas entre ambiente e processos para a conservação biológica (METZGER, 2001). Ambas se beneficiam do uso de imagens de satélite e Sistemas de Informações Geográficas (SIG).

Os avanços das tecnologias espaciais, os dados e imagens obtidas pelos sensores orbitais e tratados em SIG, tornaram-se aliados no mapeamento da cobertura vegetal e, consequentemente, dos remanescentes das coberturas naturais, neste caso, do Cerrado (MESQUITA JÚNIOR, 1998). Tais tecnologias possibilitaram o aprimoramento de métodos para obtenção de informações ecológicas da vegetação e reconhecimento da distribuição dos diversos morfotipos de vegetação em escala regional (MESQUITA JÚNIOR, 1998). 
Segundo Rosa (1992), o desenvolvimento da tecnologia de SIG possibilitou a integração e manipulação de vários dados e a construção de modelos que se modificam no tempo e no espaço. Tais modelos possibilitam a caracterização da fragmentação de uma paisagem fornecendo valores quantitativos de extensão e distribuição espacial dos diferentes tipos de fragmentos que a compõem (VALENTE, 2001). A espacialização dessas ações depende, contudo, do prévio entendimento da distribuição e das características de seus fragmentos florestais, assim como da interação desses fragmentos com os outros componentes da paisagem, ou seja, depende do entendimento da estrutura da paisagem.

Dessa maneira, o estudo da fragmentação da vegetação aproxima-se da disciplina denominada de Ecologia da Paisagem. Esta disciplina lida com a relação entre padrões espaciais e processos ecológicos, quantificando através de "métricas da paisagem ou índices da paisagem" com precisão os padrões espaciais (METZGER, 2003). A Ecologia da Paisagem, ou Geoecologia, para emprestar sua denominação original, vem promovendo uma mudança nos paradigmas dos estudos sobre fragmentação e conservação de espécies e ecossistemas, pois permite a integração da heterogeneidade espacial e do conceito de escala na análise ecológica, tornando os trabalhos mais aplicados para a resolução de reais problemas ambientais (METZGER, 2001).

Nesse contexto, as áreas que representam transformações espaciais provenientes de políticas econômicas são o foco das investigações em ecologia de paisagem, pois representam significantes alterações espaciais dos elementos naturais da paisagem em detrimento dos elementos antrópicos. Para entender melhor esses processos e perdas de serviços ecossistêmicos, objetivou-se mapear o uso do solo antrópico no município de Rio Verde, situado no estado de Goiás, Brasil, e os remanescentes das formações de Cerrado comparando as últimas três décadas. Ainda, foi realizada a comparação da dinâmica da paisagem ao longo dessas três 
décadas, com ênfase em métricas da paisagem que permitem atribuir a base para um zoneamento ambiental, mas de uma forma que ressalta tanto as áreas com maiores fragilidades ambientais quanto aquelas com maiores potencialidades ambientais.

\section{Material e métodos}

A área de estudo é o município de Rio Verde - Brasil, situado no Bioma Cerrado. O município de Rio Verde ocupa uma extensão territorial de $8.415,40 \mathrm{~km}^{2}$ e está localizado na microrregião Sudoeste do Estado de Goiás, com uma população estimada de um pouco mais de 207 mil habitantes (IBGE, 2016) (Figura 1).

Figura 1. Localização do Municipio de Rio Verde (GO)

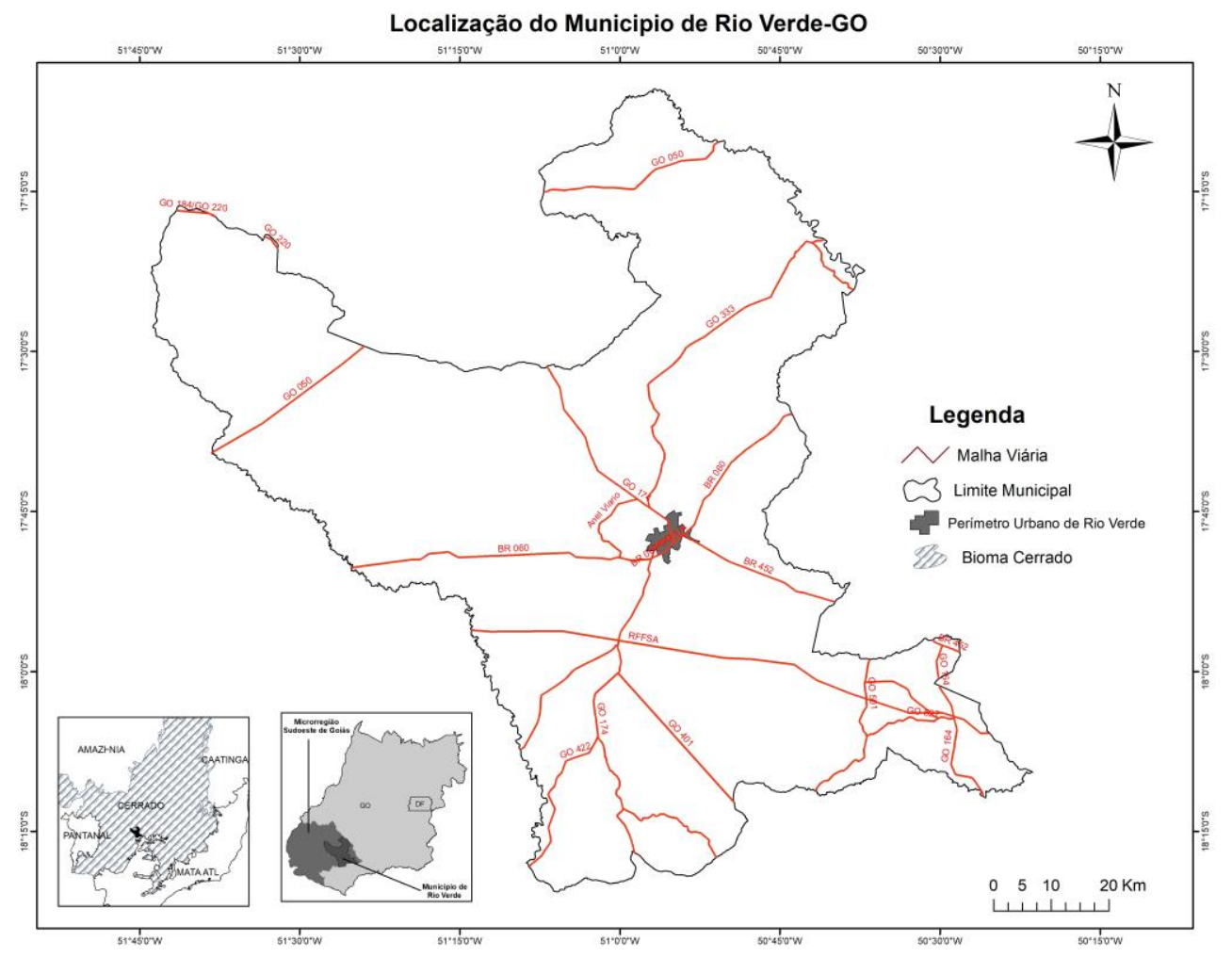

Fonte: IBGE. Base Cartográfica. Elaboração das Autoras (2019) 
Carneiro et al. (2011) constataram que na década passada (entre o ano de 2005 e 2008) a dinâmica econômica agropecuária do município de Rio Verde manteve, as grandes alterações em áreas agrícolas na paisagem, o que interferiu na dinâmica na vegetação nativa, especialmente entre fragmentos de Cerrado denso e Cerrado ralo, ambos da formação savânica.

Desta forma, para realizar o mapeamento do avanço do uso antrópico do solo e da dinâmica dos habitas naturais, foram selecionados os anos de 1987 e 2016. Para essa análise foram utilizadas imagens digitais do satélite Landsat TM com resolução espacial de 30m, bandas associadas aos canais RGB, com composição verdadeira com resposta espectral de 0,45-0,90 $\mu \mathrm{m}$, discriminados nos seguintes intervalos espectrais (azul - 0,45-0,52 $\mu \mathrm{m}$, verde - 0,52-0,60, vermelho - 0,63- 0,69 e IV próximo - 0,76-0,90). As imagens foram obtidas entre julho e outubro junto ao Instituto Nacional de Pesquisas Espaciais (INPE) para possibilitar uma melhor interpretação através da resposta espectral, devido a estacionalidade da vegetação, o que possibilita identificar acuradamente as fitofisionomias que perdem consideravelmente suas folhas nesse período.

As imagens foram classificadas no software ArcGis através da classificação em pixel, que analisa inicialmente classes de refletância subdivididas em água, área urbana, pastagem, área agrícola e vegetação de Cerrado. As principais categorias de vegetação nativa foram divididas em Formação Florestal, Savânica e Campestre (RIBEIRO; WALTER, 2008). A validação em campo foi necessária para confirmar as classes geradas através de amostras in loco e continuar as análises das métricas da paisagem.

Adicionalmente, o software Fragstats foi usado para analisar as "métricas da paisagem ou índices da paisagem" dos remanescentes, conforme proposto por McGarigal e Marks (1995). O Fragstats é um software de estatísticas espaciais gratuito projetado para quantificar a composição, a configuração e conectividade dos objetos espaciais dentro de 
uma imagem raster. Ele aceita uma imagem classificada, realiza pesquisas na imagem para buscar fragmentos contíguos de cada tipo, e então calcula um conjunto compreensivo de valores de paisagem e índices baseados nos fragmentos encontrados (HESSBURG et al., 1999). O uso desse software para análises de métricas da paisagem já vem sendo utilizadas em estudos no estado de Goiás (CARVALHO et al., 2009; CARNEIRO, et al., 2011; SIQUEIRA et al., 2017, entre outros).

Dentre as metodologias propostas na ecologia da paisagem, foram adotadas nesta pesquisa as Métricas da Fragmentação (grau de ruptura de uma unidade inicialmente contínua), as Métricas de Isolamentos (medem o isolamento de um único fragmento e o isolamento médio em relação a todas as áreas), e ainda as Métricas de Conectividade (capacidade da paisagem de facilitar fluxos biológicos) (METZGER, 2003).

\section{Resultados e discussão}

Ao interpretar as imagens de satélite de Rio Verde para os anos 1987 e 2016, foi possível perceber um significante avanço das atividades agrícolas sobre áreas de pastagem, mas principalmente sobre a vegetação nativa (Figuras 2 e 3). A pastagem não apenas perdeu espaço para atividades de agricultura, mas também migrou para áreas mais concentradas na porção sudoeste do município.

A análise das métricas de paisagem no software Fragstats foi realizada em nível de formação e não de fitofisionomia, em que é possível corroborar através da Tabela 1 o que os mapas apontam em relação ao aumento da atividade de Agricultura nos últimos 30 anos, que avançou de uma representação de 66,98\% do território de Rio Verde em 1987, para $74,59 \%$ no ano de 2016. 
Figura 2. Mapa de remanescentes de vegetação e uso antrópico do solo no município de Rio Verde, no ano de 1987

Mapa de remanescentes de vegetação de Rio Verde no ano de 1987

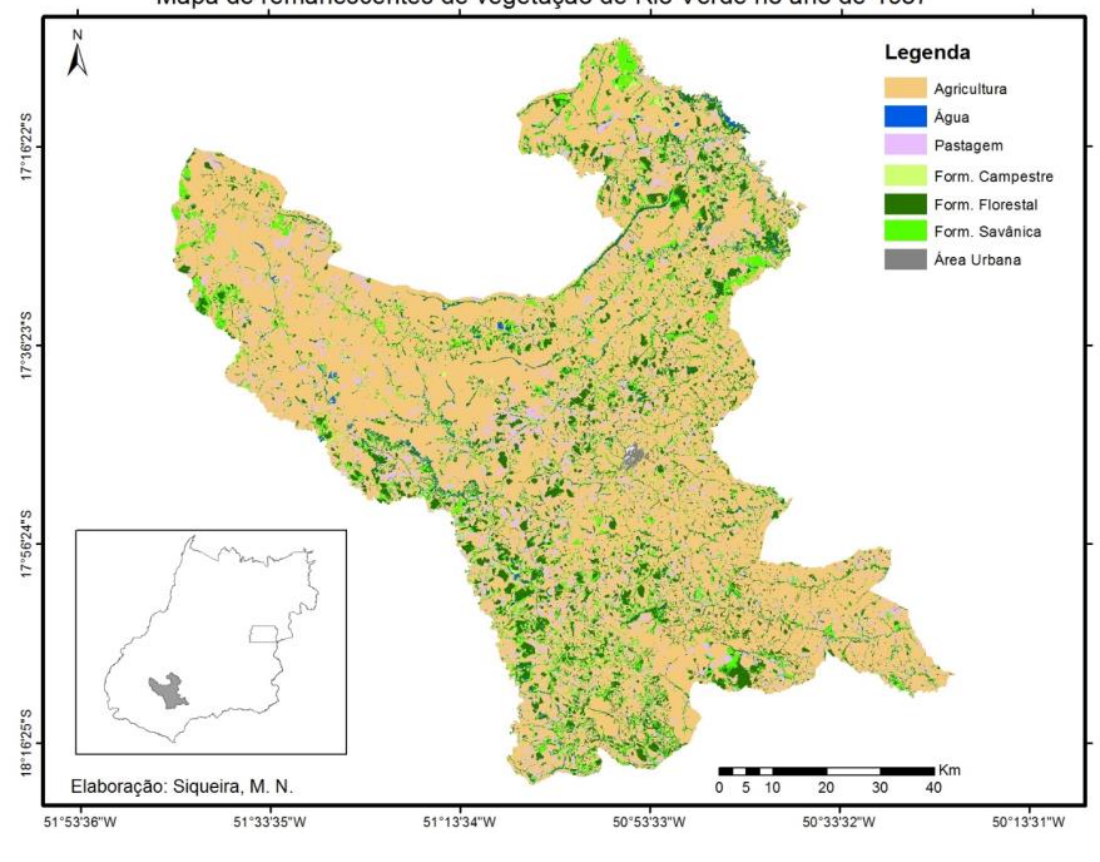

Fonte: Imagens Landsat. Elaboração: Siqueira (2016).

Figura 3. Mapa de remanescentes de vegetação e uso antrópico do solo no município de Rio Verde, no ano de 2016

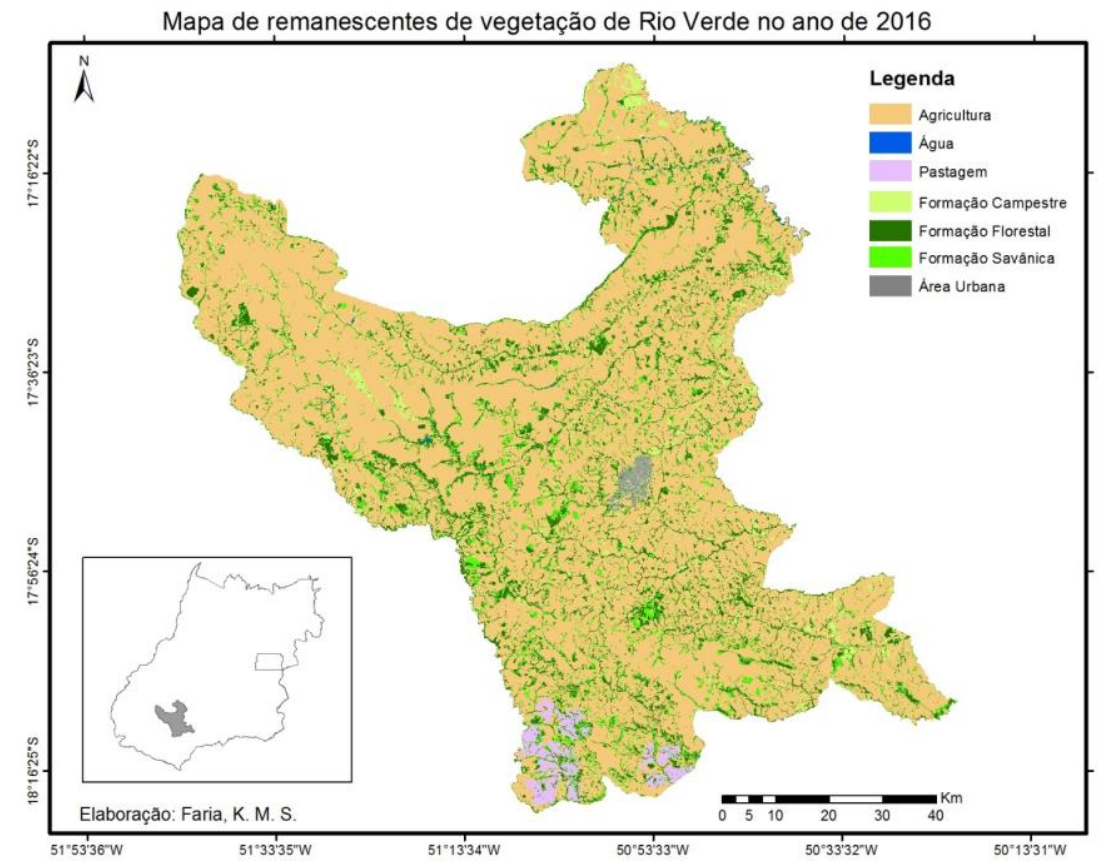

Fonte: Imagens Landsat. Elaborado por Faria (2016). 
Tabela 1. Análise das métricas de paisagem referentes às classes para os anos de $1987 \mathrm{e}$ 2016 no município de Rio Verde, Goiás.

\begin{tabular}{clllcllcr}
\hline $\begin{array}{c}\text { Métrica/ } \\
\text { Ano }\end{array}$ & Formação & \multicolumn{1}{c}{ CA } & PLAND & NP & \multicolumn{1}{c}{ TE } & \multicolumn{1}{c}{ TCA } & EMN_MN & $\begin{array}{c}\text { COHE- } \\
\text { SION }\end{array}$ \\
\hline \multirow{6}{*}{1987} & Agricultura & $561.093,12$ & 66,98 & 34.323 & 67.580 .940 & $334.692,09$ & 71,74 & 99,97 \\
& Água & $14.682,87$ & 1,75 & 25.974 & 9.235 .320 & $2.418,39$ & 126,58 & 81,61 \\
& Pastagem & $75.158,73$ & 8,97 & 85.964 & 40.717 .830 & $2.752,56$ & 86,02 & 89,32 \\
& Campestre & $21.941,82$ & 2,62 & 53.839 & 16.387 .140 & $1.401,84$ & 100,39 & 74,92 \\
& Florestal & $93.306,42$ & 11,14 & 38.213 & 29.986 .170 & $36.291,51$ & 97,90 & 93,76 \\
& Savânica & $70.264,17$ & 8,39 & 82.944 & 38.347 .020 & $11.036,43$ & 83,37 & 89,79 \\
& Urbano & $1.205,37$ & 0,14 & 40 & 111.240 & 664,74 & 436,70 & 98,86 \\
& Agricultura & $627.619,77$ & 74,59 & 14.421 & 34.850 .400 & $557.891,82$ & 79,97 & 99,97 \\
& Água & 876,51 & 0,10 & 48 & 275.850 & 319,32 & 1751,18 & 96,61 \\
& Pastagem & $12.519,63$ & 1,49 & 315 & 1.251 .630 & $8.425,44$ & 90,82 & 98,90 \\
& Campestre & $49.591,35$ & 5,89 & 68.732 & 27.032 .340 & $7.896,24$ & 94,23 & 88,56 \\
& Florestal & $95.946,93$ & 11,40 & 42.528 & 37.292 .370 & $35.268,03$ & 84,78 & 95,50 \\
& Savânica & $51.243,03$ & 6,09 & 50.803 & 27.080 .070 & $15.251,94$ & 92,35 & 87,50 \\
& Urbano & $3.606,12$ & 0,43 & 157 & 622.920 & $2.023,02$ & 75,32 & 99,29 \\
\hline
\end{tabular}

Legenda: Área de classe em hectare (CA), percentual da área de classe (PLAND), número de fragmentos da classe (NP), total de perímetros de borda em metros (TE), total de área central em hectare (TCA), distância euclidiana de vizinho mais próximo da classe (EMN_MN) e conectividades entre os fragmentos da classe (COHESION).

Fonte: Elaborado pelas autoras (2016).

A pastagem reduziu de $8,97 \%$ para $1,49 \%$, e especialmente as pequenas porções de pastagem em áreas úmidas próximas aos cursos d’água foram abandonadas e deram lugar a regeneração de formações campestres. Essa redução das áreas de pastagens condiz com a matriz agrícola do município baseada na produção de commodities.

As formações savânicas que reduziram de 8,39\% para 6,09\% também deram lugar a formações campestres, que em menor proporção também foram substituídas por áreas agrícolas. Desta forma, o aumento das áreas campestres pode ser sentido pela perda de áreas de pastagens e áreas savânicas. Por exemplo, em 2016, é possível que alguns ambientes de Parque Cerrado tornaram-se mais abertos devido ao processo de antropização e, consequentemente, foram classificados como formação campestre. A formação florestal apresentou a menor alteração, com um aumento inferior a $0,3 \%$. Um aumento similar ao da formação florestal ocorreu para a classe área urbana. 
Parque Cerrado ou Murundus, que é uma fitofisionomia bastante peculiar e sensível, uma vez que mescla formação savânica e campestre (RIBEIRO; WALTER, 2008), perdeu área no extremo nordeste do município. Estes autores classificam e caracterizam a vegetação do Cerrado e ressaltam que o bioma Cerrado é composto por fitofisionomias dispostas em três tipos de formações (florestais, savânicas e campestres). As formações savânicas propriamente ditas estão agrupadas em Cerrado sensu stricto (cerrado ralo, típico, denso e rupestre) e, em veredas, Parque Cerrado e Palmeiral. Os autores destacam que o Parque Cerrado é uma formação savânica composta por árvores agrupadas e concentradas em pequenas elevações do terreno, apresentando alturas de 3,0 a 6,0 metros, cobertura arbórea de 5 a 20\%, sob gleissolos ou plintossolos. Essas pequenas elevações do terreno são algumas vezes imperceptíveis, mas outras são mais visíveis, sendo conhecidas como murundus ou mochões.

Fragmentos de Parque Cerrado, são, portanto, ambientes prioritários para a Conservação no Estado de Goiás, porque dentre outras características peculiares, eles constituem áreas de reserva de biodiversidade, tanto da flora como da fauna, além de terem se tornado áreas legalmente protegidas como Áreas de Preservação Permanente a partir do ano de 2007 (GOIÁS, 2007). A legislação ambiental do estado de Goiás (GOIÁS, 2007; 2013) define Savana Parque como uma fitofisionomia do Bioma Cerrado que consiste em um campo úmido, em terreno pouco inclinado, com ilhas cerrado, arredondadas, com cerca de 1 (um) a 10 (dez) metros de diâmetros por centímetros de altura. Adicionalmente, destacam que esta fitofisionomia geralmente é localizada a montante de nascente e ou olhos d'água e ao longo dos mananciais.

De acordo com o regulamento que protege os ambientes de Savana Parque, qualquer supressão da vegetação ou mesmo a utilização de áreas localizadas próximas aos campos de murundus, sua drenagem, cultivo, pastoreio e outras atividades, devem manter um raio mínimo de 50 metros 
de largura ao redor destas áreas, além de passar por avaliação de impacto ambiental e licenciamento ambiental (GOIÁS, 2007).

Mesmo com o ganho de áreas florestais e campestres e a redução da formação savânica, o saldo final da vegetação nativa no ano de 2016 foi de $23,38 \%$, sendo maior que os $22,15 \%$ que recobriam o município no ano de 1986. Carneiro et al. (2011) também observaram uma dinâmica de aumento de algumas tipologias de vegetação no município de Rio Verde, ao analisar a dinâmica da paisagem entre os anos de 2005 e 2008, destacando que o saldo da vegetação nativa no município era de cerca de $22 \%$ no ano de 2008 .

Assim, é possível observar que oito anos após a análise de Carneiro et al. (2011), o município de Rio Verde ainda obteve um pequeno ganho de cobertura vegetal nativa, especialmente em áreas da porção sudeste do município, em Áreas de Preservação Permanente. Esse fato pode ser uma resposta a obrigatoriedade do Cadastro Ambiental Rural (CAR), que de acordo com Brasil (2012), trata-se do registro público eletrônico de âmbito nacional, obrigatório para todos os imóveis rurais, com a finalidade de integrar as informações ambientais das propriedades e posses rurais, compondo base de dados para o controle, monitoramento, planejamento ambiental, econômico e combate ao desmatamento. Desse modo, muitos proprietários estão isolando as áreas legalmente protegidas para evitar passivos ambientais.

Rio Verde apresentou em 2016 atividades antrópicas cobrindo 76,5\% de seu território. Ponciano et al. (2015) constataram que para o município de Mineiros, também localizado no Sudoeste de Goiás, as atividades antrópicas cobriam apenas 58,7\% do município e que a vegetação nativa ainda compreendia cerca de 41,2 \% da referida área no ano de 2012. No entanto, essa diferença pode estar associada aos solos e ao tipo de relevo que predominam nesses municípios, uma vez que Ponciano et al. (2015) destacaram que o maior percentual de vegetação nativa remanescente está sob Áreas de Preservação Permanente de drenagem ou de encosta ou 
escarpa. Já para Rio Verde, Carneiro et al. (2011) destacam o predomínio de topografia plana, sendo que Santos (2006) destaca o predomínio de latossolos.

Foi observado que o número de fragmentos (NP) entre os anos analisados reduziu cerca de 58\% para a classe de agricultura (Figura 3). Tal redução aconteceu pois o tamanho das áreas contínuas de agricultura aumentou. Os fragmentos de agricultura e a área da classe aumentou cerca de $66,7 \%$ e quase $12 \%$, respectivamente. A área de borda reduziu cerca de $50 \%$. A distância euclidiana de vizinho mais próximo para a classe agricultura é a mais baixa em relação as outras classes (79,97 metros em 2016), permanecendo quase inalterado entre os anos analisados (aumento de cerca de 9 metros), assim como a elevada conectividade que permaneceu sem alteração.

Figura 3. Diferença da evolução das Métricas da Paisagem entre 1987 e 2016 (Agricultura, Pastagem, Formações Campestre, Florestal e Savânica)

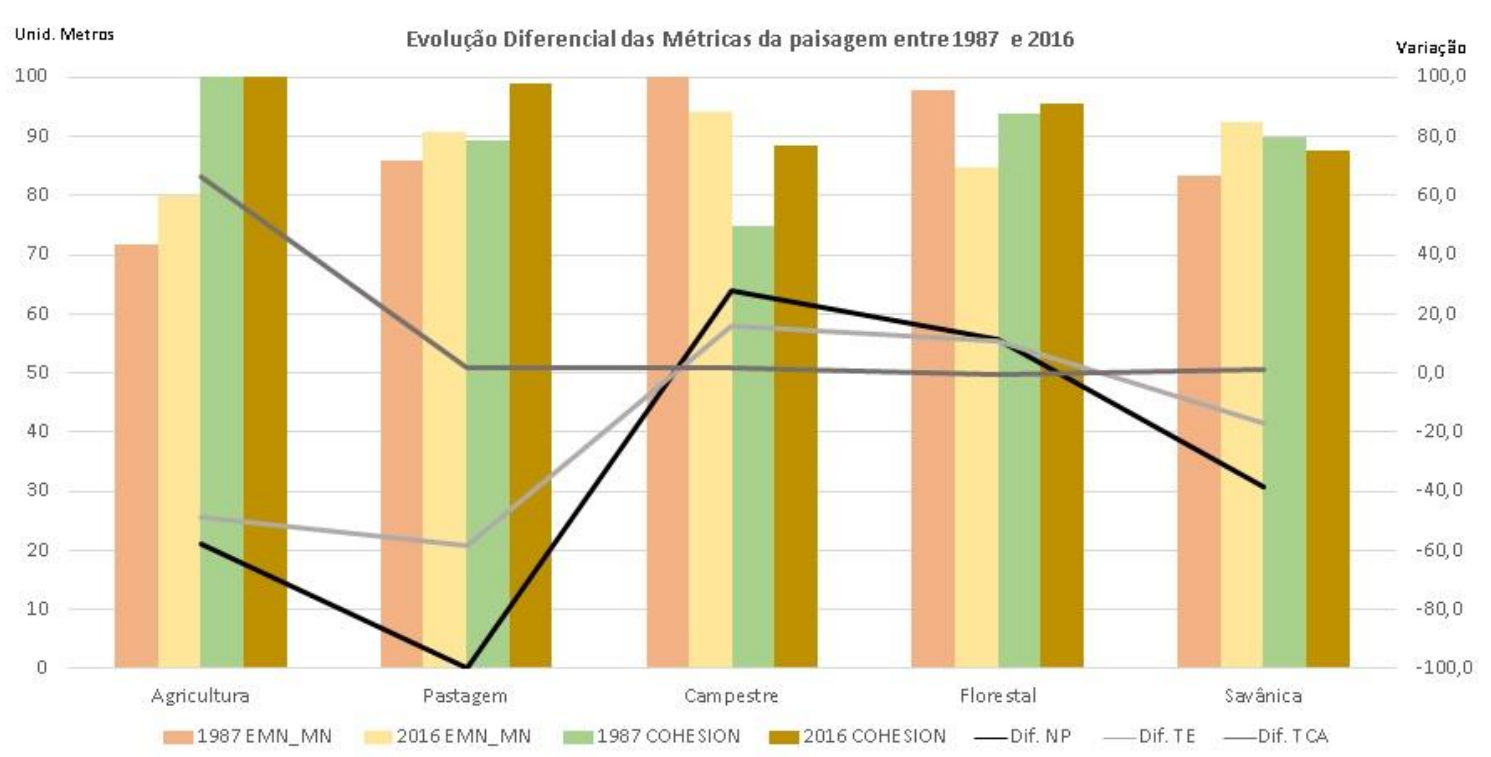

Fonte: Dados extraídos das Métricas de NP, EMN, COHESION, NP, TE e TCA e organizado pelas autoras (2018). 
A pastagem teve a mais substancial perda em área (cerca de 83\%), acompanhada de significante perda em número de fragmentos, os quais reduziram em cerca de 99\% (Tabela 1). Apesar da perda em área e em quantidade, os fragmentos de pastagem se tornam maiores (aumento de 206\% da área central desses fragmentos), com redução drástica de área de borda (redução de 97\%). Os fragmentos dessa classe apresentaram um aumento de apenas quatro metros na distância euclidiana de vizinho mais próximo e passaram a ter uma maior conectividade.

$\mathrm{Na}$ vegetação nativa, a formação campestre, que nitidamente ganhou área de formações savânicas antropizadas e áreas de pastagens abandonadas, apresentou aumento de cerca de 27,6\% em relação ao número de fragmentos (Tabela 2), aliado ao aumento de 126\% em sua área, mais um aumento de 4,6 vezes a área central desses fragmentos e ainda com aumento da área de borda em quase 65\%. Houve ainda redução da distância euclidiana de vizinho mais próximo em seis metros e aumento da conectividade, apesar de ainda ser considerada baixa a conectividade no ano de 2016 entre esses remanescentes $(88,56)$. A menor dinâmica ocorreu na formação florestal, na qual as métricas apresentaram poucas variações. Apesar de uma redução em área de 2.640,51 ha da formação florestal, a sua dinâmica em relação as métricas de paisagem foram pouco impactadas, com perda de apenas 2,8\% em sua área total. Dessa maneira, mesmo com pouca área perdida, foi o suficiente para ocasionar uma mais significante fragmentação dessa classe, aumentando em 11,3\% o número de fragmentos. A maior fragmentação levou a uma perda em área central de 2,8\%, que ocasionou o aumento em área de borda em 24,3\%. Apesar do aumento da fragmentação, os remanescentes da formação florestal tornaram-se mais próximos em cerca de 13 metros em relação à distância euclidiana de vizinho mais próximo e a conectividade também aumentou de 93,76 para 95,50.

A formação savânica sofreu grandes alterações ao longo dos anos analisados, pois perdeu cerca de $27 \%$ de sua área. Paralelamente, cerca de 
$38,7 \%$ de fragmentos se extinguiram para essa formação, permanecendo fragmentos maiores, que podem ser explicados pelo aumento da área central em cerca de $38 \%$, com a consequente redução de área de borda em quase $30 \%$. A distância dos fragmentos dessa classe aumentou em cerca de nove metros na distância euclidiana de vizinho mais próximo e, consequentemente a conectividade reduziu de 89,79 para 87,50. Já as áreas urbanas não afetam de modo considerável a análise da paisagem, assim como a classe água, dada a baixa representatividade no município de Rio Verde, apesar de existirem quatro distritos urbanos além da área urbana.

As análises da paisagem em relação à dinâmica do tamanho das manchas possibilitam compreender as tendências à fragmentação ou fusão de manchas ao longo dos anos (Tabela 2). Para os fragmentos de Agricultura, destaca-se a redução da fragmentação, uma vez que há diminuição drástica especialmente dos fragmentos menores que 10 ha (redução de cerca de 58\%). No entanto, apesar dos fragmentos maiores também apresentarem alguma redução, a concentração das terras agricultáveis em áreas maiores que 10 há é evidente, corroborando a análise da paisagem por classe.

Neste mesmo contexto, no que se refere à dinâmica dos tamanhos das manchas, a pastagem foi a classe que mais reduziu sua fragmentação, uma vez que diversas manchas menores que 10 ha despareceram ao longo dos anos analisados (99,6\% das manchas). Já a formação campestre, ao contrário da pastagem, apresentou considerável aumento da fragmentação, e as manchas menores que 10 ha aumentaram em $26,8 \%$ e, aquelas maiores que 10 ha, mas menores que 50 ha, consideravelmente aumentaram 258,5\%. As formações florestais e savânicas reduziram a fragmentação, especialmente fragmentos menores que 10 ha, uma vez que reduziram $12,8 \%$ para a formação florestal e 39,1\% para a formação savânica. 
Tabela 2. Análise das métricas de paisagem referentes ao tamanho das manchas (fragmentos) de cada classe para os anos de 1987 e 2016 no município de Rio Verde, Goiás

\begin{tabular}{|c|c|c|c|}
\hline Uso & Tamanho & NP 1987 & NP 2016 \\
\hline \multirow{5}{*}{ Agricultura } & $<1,0$ ha & 31.423 & 12.743 \\
\hline & 1,01 - 10 ha & 2.445 & 1.415 \\
\hline & $10,01-50$ ha & 344 & 182 \\
\hline & $50,01-100$ ha & 53 & 30 \\
\hline & $>100$ ha & 58 & 51 \\
\hline \multirow{5}{*}{ Pastagem } & $<1,0$ ha & 77.218 & 238 \\
\hline & $1,01-10$ ha & 7.523 & 47 \\
\hline & $10,01-50$ ha & 1.054 & 12 \\
\hline & $50,01-100$ ha & 122 & 0 \\
\hline & $>100$ ha & 47 & 18 \\
\hline \multirow{5}{*}{ Campestre } & $<1,0$ ha & 50.311 & 62.789 \\
\hline & $1,01-10$ ha & 3.371 & 5.325 \\
\hline & $10,01-50$ ha & 147 & 527 \\
\hline & $50,01-100$ ha & 8 & 59 \\
\hline & $>100$ ha & 2 & 32 \\
\hline \multirow{5}{*}{ Florestal } & $<1,0$ ha & 34.975 & 30.424 \\
\hline & 1,01 - 10 ha & 7.093 & 6.256 \\
\hline & $10,01-50$ ha & 1.150 & 1.227 \\
\hline & $50,01-100$ ha & 184 & 175 \\
\hline & $>100$ ha & 126 & 131 \\
\hline \multirow{5}{*}{ Savânica } & $<1,0$ ha & 74.394 & 42.995 \\
\hline & $1,01-10$ ha & 7.680 & 6.964 \\
\hline & $10,01-50$ ha & 734 & 768 \\
\hline & $50,01-100$ ha & 83 & 61 \\
\hline & $>100$ ha & 53 & 15 \\
\hline
\end{tabular}

Carvalho et al. (2009) registraram, para o estado de Goiás, que as paisagens dominadas pelas culturas apresentam maior fragmentação do Cerrado em relação às paisagens dominadas por pastagens. A dinâmica da paisagem em Rio Verde, corrobora essa tendência de aumento de fragmentação de remanescentes naturais de Cerrado, numa paisagem cujo percentual de agricultura transitou entre $66,98 \%$ e $74,59 \%$ entre 1987 e 2016.

Para a paisagem de Rio Verde, o grande número de manchas de vegetação nativa menores do que 10 ha é uma situação preocupante, já que 
pode haver redução na qualidade desses habitats para a biodiversidade local. Apesar de Fahrig (2003) alertar que apenas a perda de habitat é insuficiente para afirmar que haverá consequência à biodiversidade, a autora destaca que a perda de habitat aliada à fragmentação da paisagem traz consequências severas à biodiversidade. Nesse contexto, Scariot et al. (2005) complementam que as alterações negativas à biodiversidade em decorrência da fragmentação são mais significantes quando há alterações no isolamento das manchas, além de mudança na forma, no tamanho da mancha, na matriz circundante do fragmento e também o efeito de borda. Os autores destacam que essas alterações aumentam a ocorrência de perturbações naturais e antrópicas dentro do fragmento, afetando a biodiversidade e consequentemente os serviços ecossistêmicos.

Considerando que Carvalho et al. (2009) apontam que as áreas cultivadas com agricultura geram uma estrutura paisagística mais prejudicial para a conservação da biodiversidade no bioma Cerrado, é urgente pensar em um programa de conservação da biodiversidade para o município de Rio Verde. Isto porque apenas 15 fragmentos da formação savânica apresentam áreas maiores que 100 ha, sendo que para a formação florestal existem 131 fragmentos e para a formação campestre 32 fragmentos da formação campestre. Desses últimos, os covais mencionados acima (Parque Cerrado), situados no extremo nordeste do município e que apresentavam mais vegetação arbórea em 1987 quando foram classificados como formação savânica. No entanto, em 2016 suas alterações já o levaram para predomínio de formações campestres, além desses remanescentes também terem perdido área de habitat.

Diversos autores investigam a sustentabilidade de fragmentos para determinados grupos de animais e vegetais (SIQUEIRA et al., 2017; SILVA; ROCHA, 2015; SCHMIDT et al. 2012). O fato é que se a vegetação não apresentar sustentabilidade, acabará afetando as comunidades de animais e a diversidade funcional de diversos grupos de seres vivos. Nesse contexto, 
Siqueira et al. (2017) constataram que fragmentos de Cerrado Denso (uma fitofisionomia savânica) não apresentam efeitos negativos de perda de diversidade de plantas lenhosas quando áreas extensas perdem habitat e permanecem com área superior a 50 ha. Aliado a este cenário, em um amplo estudo realizado na Mata Atlântica, Magioli et al. (2015) encontraram uma relação entre diversidade funcional e tamanho de mancha de habitat, com aqueles habitats com tamanho inferior a 60 ha apresentando os menores valores de diversidade funcional para mamíferos de médio e grande porte. Cullen et al. (2005) também já sugeriam que para mamíferos de grande porte a área média de habitat para afetar minimamente as populações seria de 100 ha.

Nesta perspectiva de compreender a quantidade, localização e padrões de manchas de habitats sustentáveis no município de Rio Verde, se insere uma preocupação com a manutenção de serviços ecossistêmicos para o município, uma vez que Carvalho et al. (2009) já alertaram que matrizes agrícolas são mais prejudiciais à biodiversidade. Essa também é a realidade do município de Rio Verde. Por isso, um fator determinante em uma paisagem fragmentada é a qualidade do habitat, envolvendo a disponibilidade de recursos necessário para manter os padrões das comunidades presentes no local. Dado que a matriz agrícola de Rio Verde representa 74,59\% do município, é possível que muitos dos fragmentos menores que 10 ha sejam afetados pelo efeito de borda. Isto é proveniente de uma matriz que utiliza processos de fertilização, espécies cultivadas exóticas e insumos de ordem agressiva para a biodiversidade como os defensivos agrícolas. Então, a análise espacial da paisagem de Rio Verde precisa ser complementada por estudos ecológicos mais aprofundados, para apontar possíveis ameaças a biodiversidade, mas também para confirmar possíveis áreas prioritárias para a conservação da biodiversidade. Destaca-se também que até o presente o município de Rio Verde não apresenta qualquer área 
protegida em seu território para ampliar esses serviços ecossistêmicos, que são de elevada importância ambiental e econômica.

\section{Conclusões}

A análise da dinâmica da paisagem em Rio Verde entre os anos de 1987 e 2016 revelou padrões de perda de habitats naturais em área e em qualidade, uma vez que formações savânicas deram lugar a atividades agrícolas ou foram antropizadas, a ponto de se tornarem formações abertas e campestres. A atividade agrícola que predomina no município levou a migração das pastagens para a sua porção sudoeste, além de trazer um alerta preocupante, dado que a literatura aponta que a matrizes agrícolas trazem mais impactos negativos para a biodiversidade.

Os remanescentes de vegetação nativa estão atualmente sob pressão de atividades agrícolas e estão perdendo área, além de gerar uma vegetação mais fragmentada. É preciso pensar em conservação de áreas significativas que possibilitem a manutenção de serviços ecossistêmicos. Para isso, devem ser levadas em consideração as áreas maiores, que apresentem recursos naturais suficientes para manter a biodiversidade e a diversidade funcional nesses ambientes. $\mathrm{O}$ mapeamento e a dinâmica da paisagem ao longo destas últimas três décadas é apenas um passo inicial para compreender a localização de grandes remanescentes de habitats naturais e que sejam potenciais à conservação.

\section{Acknowledgment}

MNS e KMSF são gratas à UniRV (Universidade de Rio Verde) e CIAMB UFG (Programa de Pós-Graduação em Ciências Ambientais da Universidade Federal de Goiás) pelo auxílio financeiro, respectivamente. 


\section{Referências}

BEUCHE, R.; GRECCHI, R.C.; SHIMABUKURO, Y.E. et al. Land cover changes in the Brazilian Cerrado and Caatinga biomes from 1990 to 2010 based on a systematic remote sensing sampling approach. Applied Geography, v. 58, p. 116-127, 2015. https://doi.org/10.1016/j.apgeog.2015.01.017

BRASIL. Presidência da República. Casa Civil. Lei n. 12.651, de 25 de maio de 2012. Disponível em: <http://www.planalto.gov.br/ccivil_03/_ato2011-2014/2012/lei/112651.htm>. Acesso em: 18 abr. 2019.

CARNEIRO, G.T: CABACINHA, C.D: FARIA, K.M.S. et al. Cobertura florestal do município de Rio Verde, GO: estrutura e composição da paisagem entre 2005 e 2008. Geografia, Rio Claro, v. 36, n. 2, p. 335-357, maio/ago. 2011.

CARVALHO, F.M.V.; DE MARCO, P.; FERREIRA JUNIOR, L. G. The Cerrado into-pieces: Habitat fragmentation as a function of landscape use in the savannas of central Brazil. Biological Conservation, $\quad$ v. $\quad 142, \quad$ p. $\quad 1302-1403, \quad 2009$. https://doi.org/10.1016/j.biocon.2009.01.031

CEBALLOS, G.; EHRLICH, P.R.; BARNOSKY, A.D. et al. Accelerated modern humaninduced species losses: Entering the sixth mass extinction. Sci. Adv., v. 1, e1400253, 2015. https://doi.org/10.1126/sciadv.1400253

CULlEN, L., ABREU K. C., SANA, D. E et al. As onças-pintadas como detetives da paisagem no corredor do Alto Paraná, Brasil. Natureza \& Conservação, v. 3, n. 1, p. 4358, 2005.

DINIZ-FILHO, J. A. F., BASTOS, R. P., RANGEL, T. F. L. V. B. et al. Macroecological correlates and spatial patterns of anuran description dates in the Brazilian Cerrado. Global Ecol Biogeogr., v. 14, p. 469-477, 2005. https://doi.org/10.1111/j.1466$\underline{822 X .2005 .00165 . x}$

FAHRIG, L. Effects of habitat fragmentation on biodiversity. Annual Reviews of Ecology and Systematics, Palo Alto, v. 34, p. $487-515, \quad 2003$. https://doi.org/10.1146/annurev.ecolsys.34.011802.132419

GOIÁS (Estado). Lei n. 16.153, de 26 de outubro de 2007. Disponível em: < http://www.mp.go.gov.br/portalweb/hp/9/docs/lei_n._16.153-07_-

_campos_de_murundus_ou_covais.pdf>. Acesso em: 18 abr. 2019.

GOIÁS (Estado). Lei n. 18.104, de 18 de julho de 2013. Disponível em: < http://www.gabinetecivil.goias.gov.br/leis_ordinarias/2013/lei_18104.htm>. Acesso em: 18 abr. 2019.

HESSBURG, P.F.; SMITH, B.G.; SALTER, R.B. Using Natural Variation Estimates to Detect Ecologically Important Change in Forest Spatial Patterns: A Case Study of the Eastern Washington Cascades. Portland, USA: Department of Agriculture, Forest Service, Pacific Northwest Research Station: Portland, 1999. p. 65. https://doi.org/10.2737/PNW-RP-514

IBGE. Instituto Brasileiro de Geografia e Estatística. 2016. Disponível em < http://cidades.ibge.gov.br/xtras/perfil.php?codmun=521880>. Acesso em: 23 jan. 2016.

MAGIOLI, M.; RIBEIRO, M. C.; FERRAZ, K. M. P. M. B.; et al. Thresholds in the relationship between functional diversity and patch size for mammals in the Brazilian Atlantic Forest. Animal Conservation, v 18, n. 6, p. 499-511, 2015. https://doi.org/10.1111/acv.12201

MCGARIGAL, K.; MARKS, B. Fragstats: Spatial Pattern Analysis Program for Quantifying Landscape Structure. [S.1.]: US Dept. of Agriculture, Forest Service, Pacific Northwest Research Station, 1995. https://doi.org/10.2737/PNW-GTR-351

MESQUITA JUNIOR, H.N. de. Análise temporal com sensor orbital de unidades fisionômicas de cerrado na gleba Grande Pé de Gigante (Parque Estadual de Vassunga-SP). 1998. 128 f. Dissertação (Mestrado em Ecologia dos Ecossistemas 
terrestres e aquáticos) - Instituto de Biociências, Universidade de São Paulo, São Paulo, 1998.

METZGER, J. P. O que é ecologia de paisagens. Biota Neotropica, v. 1, n. 1. BN00701122001, 2001. https://doi.org/10.1590/S1676-06032001000100006

METZGER, J. P. Estrutura da paisagem: uso adequado de métricas. In: CULLEN JUNIOR, L., PÁDUA, C. V.; RUDRAN, R. Métodos de estudos em biologia da conservação e manejo da vida silvestre. Curitiba: Ed. UFPR; Fundação O Boticário de Proteção à Natureza, 2003. p. 539-553. 667 p.

MITTERMEIER, R.A.; GIL, P.R.; HOFFMANN, M. et al. Hotspots revisited: earth's biologically richest and most endangered terrestrial ecoregions. Natureza \& Conservação, v. 3, n. 1, p 43-58, 2005.

PONCIANO, T. A.; FARIA, K. M.; SIQUEIRA, M. N. et al. Fragmentação da cobertura vegetal e estado das Áreas de Preservação Permanente de canais de drenagem no Município de Mineiros, Estado de Goiás. Ambiência. Revista do Setor de Ciências Agrárias e Ambientais, v. 11, n .3, set./dez. 2015.

RIBEIRO, J. F.; WALTER, B.T. As principais fitofisionomias do bioma Cerrado. In: SANO, S. M; ALMEIDA, S. P.; RIBEIRO, J. F. Cerrado: ecologia e flora. Brasília: 2008. p. 151212.

ROSA, R. Introdução ao sensoriamento remoto. 2. ed. Uberlândia: EDUFU, 1992.

SANTOS, L. O. Mapas de uso da terra do Município de Rio Verde Anos de 1975 e 2005.

SANTOS, T. C.; CÂMARA, J.B.D. Perspectivas do Meio Ambiente no Brasil. Brasília: Edições IBAMA, 2002.

SCARIOT, A.; FREITAS, S. R.; NETO, E. M. et al. Vegetação e flora. In: RAMBALDI, D. M.; OLIVEIRA, D. A. S. (Org.). Fragmentação de ecossistemas: causas, efeitos sobre a diversidade e recomendações de políticas públicas. 2. ed. Brasília: MMA/SBF, 2005. p. 103$123,2005$.

SCHMIDT, D. G.; COSTA, L. C.; ELPINO-CAMPOS, A.; BARP, E. Diversidade de borboletas (lepidoptera) na borda e no interior de um fragmento de mata, no município de Seara - SC. Saúde Meio Ambient., v. 1, n. 2, dez. 2012. https://doi.org/10.24302/sma.v1i2.263

SILVA, J.; ROCHA, E.C. Influência de métricas estruturais da paisagem na riqueza de espécies de mamíferos de médio e grande porte em fragmentos de Cerrado, no Sudeste de Goiás. In: CONGRESSO DE ENSINO, PESQUISA E EXTENSÃO DA UEG, 2., 2015, Pirenópolis. Anais... Pirenópolis: UEG, 2015.

SIQUEIRA, M.N.; CASTRO, S.S.; MORAIS, A.R.; et al. 2017. Woody plant community structure in Dense Cerrado fragments in the Upper Basin of the Araguaia River (Central Brazil): relationship with habitat loss and geographic distance. Brazilian Journal of Botany, v. 40, n.717, 2017. p 717-725. https://doi.org/10.1007/s40415-017-0378-z

SOARES-FILHO, B.; RAJÂO, R.; MACEDO, M. et al. Cracking Brazil's Forest Code. Science, v. 344, Apr. 2014. https://doi.org/10.1126/science.1246663

VALENTE, R. DE O. A. Análise da estrutura da paisagem na bacia do rio Corumbataí, SP. 2001. 144f. Dissertação (Mestrado) - Escola Superior de Agricultura Luiz Queiroz, Universidade de São Paulo, São Paulo, 2001. 